www.neuropsychopharmacology.org

\section{Obituary Billy R Martin}

Neuropsychopharmacology (2009) 34, 2779; doi: I 0. I038/npp.2008.203

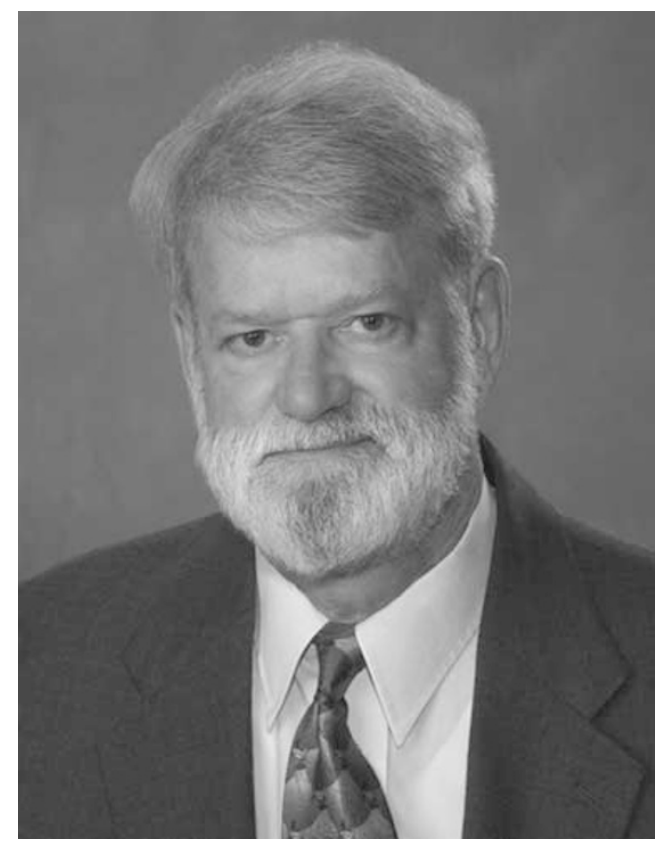

Billy R Martin, husband, father, friend, and world renowned scientist and educator died at his home on 8 June 2008. Billy was born in Kernersville North Carolina on 25 April 1943. He earned an $\mathrm{AB}$ in Chemistry and a PhD in Pharmacology from the University of North Carolina at Chapel Hill. His loyalty to that institution lasted throughout his life and was only surpassed by his devotion to his family and his friends.

For his doctoral dissertation, Billy performed seminal work to show that the pronounced tolerance to $\delta$-9tetrahydrocannabinol was a pharmacological tolerance in the neurons of the central nervous system and not a metabolic or distributional tolerance, which had been hypothesized. He continued his training in cannabinoid pharmacology at the University of Uppsala in Sweden and at Oxford University in England. He became an assistant professor of pharmacology at Virginia Commonwealth University in 1976 and rose through the ranks to become full professor in 1987 and chair of the department in 2000.

Billy was universally recognized as one of the top pharmacologists in the field of cannabinoid research and added significantly to our knowledge of the mechanism of action of nicotine and other drugs of abuse. He characterized the dependence liability of cannabinoids and with the leading chemists in the field as collaborators, carried out an extensive investigation of the structure-activity relationships of these interesting compounds. His methodology for the characterization of the pharmacological profile of cannabinoids has been used by most scientists working in this field. It clearly is the standard of practice.

Billy carried out the definitive pharmacological, cellular, and molecular investigations of the first identified endogenous cannabinoid, anandamide. He demonstrated that tolerance developed and a withdrawal syndrome existed following the cessation of its chronic administration. He demonstrated and characterized the existence of two types of cannabinoid receptor and recently presented evidence of a third receptor.

He combined receptor-binding assays with classical pharmacological models in whole animals to characterize the reinforcing effects of nicotine and similar compounds. He along with other chemists as collaborators did an exhaustive structure-activity relationship that provided a much better understanding of the nicotinic receptor and defined the structural requirements for nicotinic agonists and antagonists.

Billy published over 400 papers, chapters, and reviews. His scholarly work was very well funded throughout his career. He earned a MERIT award, and was the principal investigator on a center grant and a program project grant studying various aspects of the pharmacology of cannabinoids. He also earned an RO1 grant to characterize the acute and chronic effects of abused drugs taken by inhalation and other grants to study nicotine. The list of his collaborators from this and other countries is most impressive. He served as chair of study sections, as field editor for the Journal of Pharmacology and Experimental Therapeutics, and was elected president of two international scholarly organizations, The College on Problems of Drug Dependence and The International Cannabinoid Research Society.

Billy was honored by his university with their awards of scholarship and overall excellence, by the Commonwealth of Virginia as its outstanding scientist, by The College on Problems of Drug Dependence (CPDD) with the Nathan B Eddy Award, and by The International Cannabinoid Research Society (ICRS) by the Mechoulam Award. Billy was a distinguished neuropharmacologist and friend who will be missed by numerous scientists throughout the world but most by those of us who had the pleasure to work with him daily for many years.

\footnotetext{
William L Dewey ${ }^{1}$

${ }^{1}$ Department of Pharmacology and Toxicology, Virginia Commonwealth University, Richmond, VA, USA
} 